\title{
Repeated intranasal TLR7 stimulation reduces allergen responsiveness in allergic rhinitis
}

\author{
Lennart Greiff* ${ }^{*}$, Anders Cervin², Cecilia Ahlström-Emanuelsson', Gun Almqvist, Morgan Andersson', Jan Dolata², \\ Leif Eriksson ${ }^{3}$, Edward Högestätt ${ }^{4}$, Anders Källén ${ }^{3}$, Per Norlén ${ }^{3}$, Inga-Lisa Sjölin² and Henrik Widegren ${ }^{1}$
}

\begin{abstract}
Background: Interactions between Th1 and Th2 immune responses are of importance to the onset and development of allergic disorders. A Toll-like receptor 7 agonist such as AZD8848 may have potential as a treatment for allergic airway disease by skewing the immune system away from a Th2 profile.

Objective: To evaluate the efficacy and safety of intranasal AZD8848.

Methods: In a placebo-controlled single ascending dose study, AZD8848 (0.3-600 $\mu \mathrm{g})$ was given intranasally to 48 healthy subjects and 12 patients with allergic rhinitis (NCT00688779). In a placebo-controlled repeat challenge/ treatment study, AZD8848 (30 and $60 \mu \mathrm{g}$ ) was given once weekly for five weeks to 74 patients with allergic rhinitis out of season: starting 24 hours after the final dose, daily allergen challenges were given for seven days (NCT00770003). Safety, tolerability, pharmacokinetics, and biomarkers were monitored. During the allergen challenge series, nasal symptoms and lavage fluid levels of tryptase and $a_{2}$-macroglobulin, reflecting mast cell activity and plasma exudation, were monitored.

Results: AZD8848 produced reversible blood lymphocyte reductions and dose-dependent flu-like symptoms: 30 $100 \mathrm{\mu g}$ produced consistent yet tolerable effects. Plasma interleukin-1 receptor antagonist was elevated after administration of AZD8848, reflecting interferon production secondary to TLR7 stimulation. At repeat challenge/ treatment, AZD8848 reduced nasal symptoms recorded ten minutes after allergen challenge up to eight days after the final dose. Tryptase and $a_{2}$-macroglobulin were also reduced by AZD8848.
\end{abstract}

Conclusions: Repeated intranasal stimulation of Toll-like receptor 7 by AZD8848 was safe and produced a sustained reduction in the responsiveness to allergen in allergic rhinitis.

Trial registration: NCT00688779 and NCT00770003 as indicated above.

Keywords: Allergy, Immunity, Seasonal, Toll-like receptor 7, Treatment

\section{Background}

As suggested by the hygiene hypothesis, infections are of importance to the maturation of the immune system [1]. Th1-mediated immunity may be defective in a modern clean environment resulting in facilitation of Th2 responses associated with allergic disorders [2,3]. Conversely, up-regulated Th1 responses, e.g. as a consequence of infections, can be associated with reduced Th2 activity and reduced responsiveness to allergen [4]. Controlled

\footnotetext{
* Correspondence: lennart.greiff@live.se

1Department of ORL, Head \& Neck Surgery, Skane University Hospital, Lund, Sweden

Full list of author information is available at the end of the article
}

infection-like stimulation of the immune system may in this context be beneficial, and may be achieved by the use of Toll-like receptor (TLR) agonists.

TLRs are receptors of the innate immune system that recognise conserved microbial components known as pathogen-associated molecular patterns (PAMPs) [5]. PAMPs include the bacterial product LPS, viral singlestranded RNA, and bacterial/viral CpG DNA, acting as TLR4, TLR7, and TLR9 ligands, respectively [6]. Activation of TLRs stimulates the innate immune system, potentially leading to down regulation of Th2 adaptive responses to allergen [6]. The possibility of skewing the immune system away from a Th2 response, as has been

\section{Biomed Central}


attempted previously by other measures [7-10], is the basis for the development of TLR agonists as treatments for allergic rhinitis and asthma.

In a murine model of allergic asthma, a TLR7 ligand (S28463) administered systemically exerted anti-allergic effects resulting in attenuated airway eosinophilia, normalized airway responsiveness, and prevention of airway remodelling [11,12]. In a similar model, Sel et al. [13] demonstrated that systemic intervention with poly(I:C) and R-848, viral ligands recognized by TLR3 and TLR7 respectively, prevented production of allergen specific IgE and IgG1 during sensitisation and subsequently alleviated experimental asthma. Moreover, administration of poly(I:C) and R-848 in established allergy markedly reduced the responsiveness to allergen [13]. Similarly, the TLR9 ligand 1018 ISS was shown to inhibit Th2mediated airway inflammation and hyperresponsiveness in animals [14-18].

AZD8848 is a selective TLR7 agonist optimised for topical airway treatment through rapid metabolism by plasma esterases, thereby reducing systemic exposure [19]. Observations involving peripheral blood mononuclear cells (PBMCs) and ovalbumin-sensitized splenocytes indicate that stimulation of TLR7 by AZD8848 inhibits Th2-adaptive responses to allergen via an immune response involving the induction of mediators including interferon alpha (IFN- $\alpha$ ) [19-22]. Furthermore, Ikeda et al. [23] reported that AZD8848 was effective against allergen-induced airway obstruction and inflammation in guinea-pig models of rhinitis and asthma with weekly as well as acute dosing.

Here, we report the results of two studies. In the first study, increasing single doses of AZD8848 were administered intranasally to healthy subjects and patients with allergic rhinitis. Indices of efficacy and tolerance were monitored. In the second study, AZD8848 was administered intranasally once weekly for five weeks to patients with allergic rhinitis: these individuals were then subjected to repeat allergen exposure and disease activity was monitored focusing on symptoms to establish proof of principle.

\section{Methods}

\section{Study description}

This report comprises two studies evaluating safety and efficacy of single and repeated doses of AZD8848 administered to the nasal airway, both approved by the Regional Ethics Committee and the Swedish Medical Product Agency. They were conducted according to the Declaration of Helsinki and in compliance with Good Clinical Practice, and informed consent was obtained. The studies were of randomized, placebo-controlled, double-blinded, and parallel group designs. Reprotoxicology data was lacking for AZD8848 at the time of these studies and men only were recruited.

\section{Single ascending dose study (NCT 00688779) Subjects}

Eight single ascending intranasal doses of AZD8848 (0.3$600 \mu \mathrm{g})$ were given to healthy subjects $(\mathrm{n}=48$, mean age 26, range 19-44), in groups each involving four individuals receiving AZD8848 and two receiving placebo. Once a maximum tolerated dose was determined, patients with allergic rhinitis $(n=12$, mean age 25 , range 22-28) received single doses of AZD8848 (30 and $100 \mu \mathrm{g})$ and placebo.

Exclusion criteria for healthy individuals were: any relevant disease including seasonal and perennial allergic rhinitis, asthma, clinically relevant structural nasal abnormalities, and upper respiratory tract infection within two weeks prior to the start of the study.

Inclusion criteria for patients were: men with seasonal allergic rhinitis for at least two years, positive skin prick test to birch or grass pollen allergen, asymptomatic condition outside the pollen season, and need for treatment at seasonal allergen exposure.

Exclusion criteria for patients were: any relevant disease including perennial allergic rhinitis, asthma, clinically relevant structural nasal abnormalities, upper respiratory tract infection within two weeks prior to the start of the study, use of topical corticosteroids within four weeks prior to the study and use of antihistamines within one week, and immunotherapy.

\section{Study drug}

The study product was a solution of AZD8848 $(60 \mathrm{mg} / \mathrm{g})$, diluted with sterile buffered saline to concentrations required for each dose level. It was administered using a nasal spray device delivering $50 \mu \mathrm{L}$ per actuation. The placebo product was isotonic saline. The study product was provided in $10 \mathrm{~mL}$ amber glass vials fitted with pump spray devices. In order to assure compliance, study personnel administered the doses. To prevent bronchial airway deposition of the drug, the patients were instructed to exhale against a resistance (30 $\mathrm{cm} \mathrm{H} \mathrm{H}_{2}$ ), to functionally close the connection between the nasal and bronchial airways, while the study drug was administered.

\section{Measurements}

Pharmacokinetic parameters were monitored. Furthermore, plasma interleukin-1 receptor antagonist (IL-1Ra) was measured, reflecting type-1 IFN generation downstream from TLR7, and blood lymphocyte counts were carried out. An extensive safety investigation was performed with laboratory measurements (haematology, clinical chemistry, and urine analysis), inspection of the 
nose (before and 24 hours after dose), vital signs (blood pressure, pulse, and body temperature), and continuous ECG. Finally, AEs were monitored and recorded with information about seriousness, causality, intensity, action taken, recovery, and outcome.

\section{Repeat challenge/treatment study (NCT 00770003) Subjects}

AZD8848 was given once per week for five weeks. In a first part (Part A), 18 patients were assessed at two dose levels (30 and $60 \mu \mathrm{g}$ ) (mean age 24 years, range 19-39) (Table 1). These individuals were resident at the clinic until 24 hours after each dose and subjected to intense safety monitoring. Of these subjects six received $30 \mu \mathrm{g}$ AZD8848, six $60 \mu \mathrm{g}$ AZD8848, and six placebo. In a second part (Part B), 56 patients were examined in an outpatient setting: 28 received $60 \mu \mathrm{g}$ AZD8848 and 28 received placebo (Table 1 ). In both groups (Part A as well as B), starting 24 hours after the final dose, daily allergen challenges were performed for seven days. Data from Part $B$ were analyzed together with the twelve subjects from Part $A$ who either received $60 \mu \mathrm{g}$ AZD8848 or placebo: progress through the Repeat challenge/ treatment study is described in Figure 1. The mean age of these 68 patients was 27 years (range 18-46). Inclusion and exclusion criteria for the patients were the same as described in the dose finding study above for patients with allergic rhinitis.

\section{Study drug}

The study product was AZD8848 (0.3 and $0.6 \mathrm{mg} / \mathrm{mL}$ ) in buffered saline. It was administered using a nasal spray device delivering $50 \mu \mathrm{L}$ per actuation. The placebo product had the same composition except for AZD8848. In Part A, 30 or $60 \mu \mathrm{g}$ AZD8848 was administered once per week for five weeks (i.e. 15 or $30 \mu \mathrm{g}$ per nasal cavity). In Part B, $60 \mu \mathrm{g}$ AZD8848 was given once per week for five weeks (i.e. $30 \mu \mathrm{g}$ per nasal cavity). In order to assure compliance, study personnel administered all doses. To prevent bronchial airway deposition of the drug, the patients were instructed to exhale against a resistance (30 $\mathrm{cm} \mathrm{H}_{2} \mathrm{O}$ ), to functionally close the connection between the nasal and bronchial airways, while the study drug was administered.

\section{Measurements 1}

Pharmacokinetic characteristics were explored only in Part A ( $\mathrm{n}=18)$. AZD8848 was not expected to be detectable in plasma due to rapid and complete metabolism. Therefore, exposure was monitored through analysis of its acid metabolite. Blood samples were obtained before and 15 minutes and 0.5, 1.0, 1.5, 2.0, and 4.0 hours after the first and fifth study drug administration in Part A. Analysis of AZD8848 and its acid metabolite was performed using ethanol extraction followed by liquid chromatography and tandem mass spectrometry.

Plasma samples for analysis of IL-1Ra were obtained during the Part $A$ study period prior to and 24 hours following the first, third, and fifth administration of the study drug. In Part $A(\mathrm{n}=18)$, the same safety variables were monitored as in the single ascending dose study. In Part $B$, safety monitoring was reduced to vital signs, clinical chemistry, and ECG at pre-dose, prior to the third dose, 24 hours after the fifth dose, and at follow-up. In addition, a flow-cytometric analysis of lymphocyte subsets was performed. AEs were recorded continuously in both groups as described for the single ascending dose study above.

\section{Allergen challenge model}

In order to establish individually tolerable, repeatable, yet symptom-producing allergen challenge-doses, a nasal titration procedure was performed [24]. In the allergen titration scheme, increasing doses of birch or grass pollen allergen were administrated at ten-minute intervals using a spray-device delivering $100 \mu \mathrm{L}$ per actuation (Aquagen, ALK-Abelló, Hørsholm, Denmark). One puff was administered into each nostril resulting in effective doses of 100 , 300, 1.000, and 3.000 SQ units per nasal cavity. This scheme was followed until the subject responded with at

Table 1 Design of the repeat challenge/treatment study (Part A and B)

\begin{tabular}{|c|c|c|c|c|c|c|c|c|c|c|c|c|c|c|c|c|c|c|c|c|c|c|c|c|c|c|c|c|c|c|c|c|c|c|c|c|c|}
\hline \multirow[t]{2}{*}{ Study week } & \multicolumn{7}{|l|}{1} & \multicolumn{7}{|l|}{2} & \multicolumn{7}{|l|}{3} & \multicolumn{7}{|l|}{4} & \multicolumn{7}{|l|}{5} & \multicolumn{2}{|l|}{6} \\
\hline & 1 & 2 & 3 & 4 & 5 & 6 & 7 & 1 & 2 & 3 & 4 & 5 & 6 & 7 & 1 & 2 & 3 & 4 & 5 & 6 & 7 & 1 & 2 & 3 & 4 & 5 & 6 & 7 & 1 & 2 & 3 & 4 & 5 & 6 & 7 & 1 & 2 \\
\hline Treatment & $x$ & & & & & & & $x$ & & & & & & & $x$ & & & & & & & $x$ & & & & & & & $X$ & & & & & & & & \\
\hline Allergen & & & & & & & & & & & & & & & & & & & & & & & & & & & & & & $x$ & $x$ & $x$ & $X$ & $x$ & $X$ & $x$ & \\
\hline Symptoms & & & & & & & & & & & & & & & & & & & & & & & & & & & & & & $x$ & $x$ & $x$ & $X$ & $x$ & $X$ & $x$ & $x$ \\
\hline Plasma & $x$ & $X$ & & & & & & & & & & & & & $x$ & $x$ & & & & & & & & & & & & & $x$ & $x$ & & & & & & & \\
\hline Nasal lavage & $x$ & & & & & & & & & & & & & & & & & & & & & & & & & & & & $x$ & & & & & & & & $x$ \\
\hline
\end{tabular}

Nasal symptoms were scored ten minutes after each allergen challenge as well as every morning and evening during the seven days' allergen challenge series. Note that post challenge and evening symptoms were recorded from day 2 of Study week 5 to day 1 of Study week 6, while morning symptoms were recorded from day 3 of Study week 5 to day 2 of Study week 6 . On the first days of Study weeks 1 and 5 nasal lavages were carried out prior to administration of the study drug. The plasma samples were used to monitor safety parameters, pharmacokinetics, and IL-1Ra. 


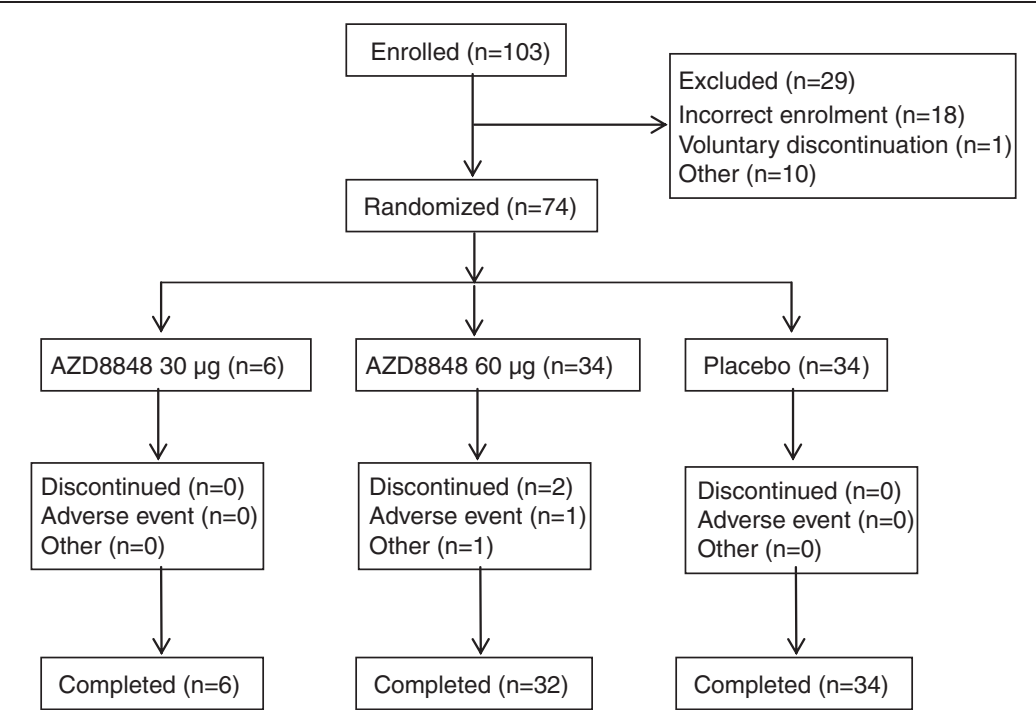

Figure 1 Patient flow through the repeat challenge/treatment study (participants in Part A as well as Part B). The progress was characterized by very few dropouts (2.7\%).

least 5 sneezes or recorded a symptom score of 2 or more on a scale from 0 to 3 for either nasal secretion or nasal blockage. The dose that produced the desired effect was chosen for the allergen challenge series and was given in the morning once daily for seven days, starting 24 hours after the final dose of the study drug.

\section{Measurements 2}

During the allergen challenge series, the patients scored nasal symptoms every morning and evening. The scores were entered into diary cards and each registration reflected the preceding twelve hours. Nasal secretion and blockage as well as the most severe of sneezing and itching were scored separately on a four-grade scale: $0=$ no, 1 = mild, $2=$ moderate, and $3=$ severe symptoms . The scores were added to a daily total nasal symptom score (TNSS), with separate morning and evening scores. Nasal symptoms were also scored ten minutes post allergen challenge: secretion and blockage were scored as described above, whereas the number of sneezes were counted and transformed into a sneezing score by the investigators: 0 sneezes $=0,1-4$ sneezes $=1$, $5-9$ sneezes $=2$, and 10 or more sneezes $=3$. The scores were added to a daily post challenge TNSS.

Nasal saline lavages were obtained at three occasions, i.e. prior to administration of the study drug (baseline observation), 24 hours after the final dose, and 24 hours after the final allergen challenge. Nasal lavages were carried out using a pool-device containing $15 \mathrm{~mL}$ fluid and the right nasal cavity was used at all occasions [25]. Each lavage had a five-minute duration. The recovered lavage fluids were centrifuged and the supernatants were homogenized, prepared in aliquots, and frozen $\left(-30^{\circ} \mathrm{C}\right)$. The samples were subjected to analysis of $\alpha_{2}$-macroglobulin and tryptase, reflecting plasma exudation and mast cell activity, respectively.

$\alpha_{2}$-Macroglobulin in nasal lavage fluids was measured using a radioimmunoassay sensitive to $7.8 \mathrm{ng} / \mathrm{mL}$. Tryptase was measured using a radioimmunoassay with detection limit of $0.5 \mathrm{ng} / \mathrm{mL}$ (Pharmacia-Diagnostics, Uppsala, Sweden). While $\alpha_{2}$-macroglobulin was analysed in the lavage fluids as they were, samples were concentrated ten times before the analysis of tryptase. In plasma, IL-1Ra was measured using a commercial ELISA (Invitrogen, Carlsbad, CA).

\section{Statistics}

In the single ascending dose study, only descriptive statistics were used. Similarly, descriptive statistics only were employed for pharmacokinetic observations and safety variables. In the repeat challenge/treatment study, an ANOVA model was used for comparison between treatments (AZD8848 $60 \mu \mathrm{g}$ vs. placebo): TNSS recorded post challenge and at morning and evening observations were analyzed separately. P-values refer to one-sided hypothesis testing: values $<0.05$ were considered statistically significant. A multiplicative model was used for biomarkers by $\log$ transformation of the response variable and the covariate (i.e. a baseline value). If there was a value below limit of quantification (LOQ) in this analysis, it was estimated to LOQ/2. Treatment differences were estimated from respective model and confidence intervals, and p-values were calculated. In the repeat challenge/treatment study, the six 
patients receiving AZD8848 $30 \mu \mathrm{g}$ per week were not included in the comparative analysis as they were so few.

\section{Results}

Single ascending dose study

AZD8848 was not measurable in plasma, whereas its acid metabolite was readily detected. For the 30 and $100 \mu \mathrm{g}$ doses, respectively, mean maximum plasma concentration $\left(C_{\max }\right)$ was 0.27 and $0.65 \mathrm{nmol} / \mathrm{L}$, time to $C_{\max }\left(t_{\max }\right)$ was 15.0 and $22.5 \mathrm{~min}$, and half-life $\left(t_{1 / 2}\right)$ was 18.4 and $27.6 \mathrm{~min}$ in healthy volunteers. Mean $C_{\max }$ increased with increasing dose levels to a maximum of $1.55 \mathrm{nmol} / \mathrm{L}$ with the $600 \mu \mathrm{g}$ dose. Area under the curve (AUC) increased roughly linearly with ascending dose.

The first dose that consistently produced systemic effects in terms of lymphocyte reductions (Figure 2A) and elevations of plasma IL-1Ra (data not shown) was

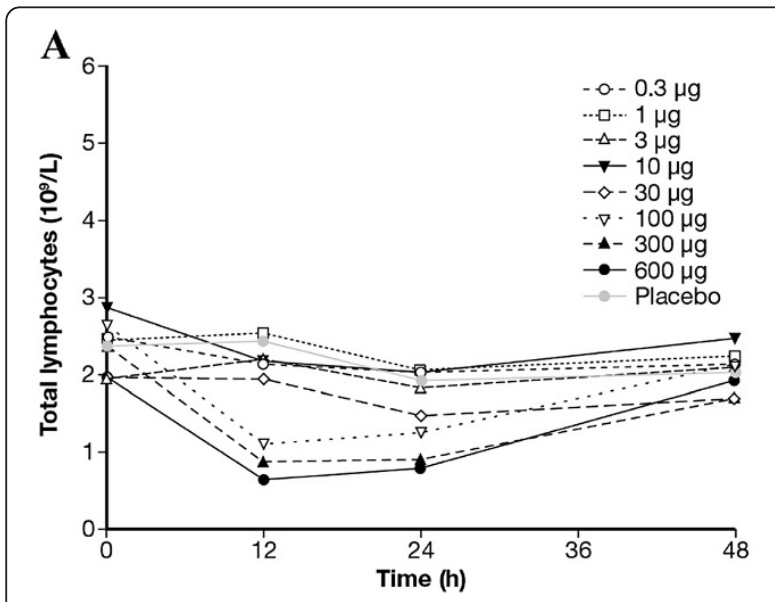

\section{B}

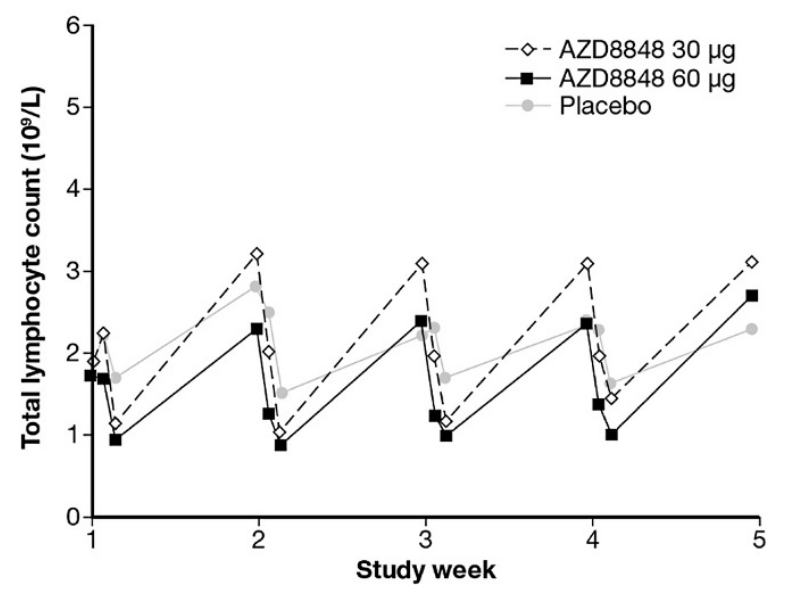

Figure 2 Mean blood lymphocyte counts in the dose finding study (A) and the repeat challenge/treatment study (B). AZD8848 produced dose-dependent and repeatable lymphocyte reductions. The reductions were reversible and global, involving CD3+, CD4+, CD8+, and CD20+ cells (data not shown).
Table 2 Side effects of different doses of AZD8848 in healthy subjects (the single ascending dose study): each group comprised four individuals and the figures indicate the number of subjects reporting a particular experience (by preferred term)

\begin{tabular}{lllllllll}
\hline & \multicolumn{7}{l}{ Dose $(\boldsymbol{\mu g})$} \\
\cline { 2 - 8 } & $\mathbf{0 . 3}$ & $\mathbf{1}$ & $\mathbf{3}$ & $\mathbf{1 0}$ & $\mathbf{3 0}$ & $\mathbf{1 0 0}$ & $\mathbf{3 0 0}$ & $\mathbf{6 0 0}$ \\
\hline Headache & 1 & 0 & 0 & 1 & 0 & 3 & 3 & 4 \\
Epistaxis & 1 & 0 & 0 & 0 & 1 & 1 & 1 & 4 \\
Pharyngeal pain & 0 & 0 & 0 & 0 & 1 & 0 & 0 & 3 \\
Pyrexia & 0 & 0 & 0 & 0 & 0 & 2 & 1 & 3 \\
Rhinorrhea & 0 & 0 & 0 & 0 & 0 & 2 & 1 & 2 \\
Nasal blockage & 0 & 0 & 0 & 0 & 2 & 1 & 0 & 0 \\
Nasal ulcer & 0 & 0 & 0 & 0 & 0 & 0 & 2 & 1 \\
Nasopharyngitis & 1 & 0 & 0 & 0 & 0 & 0 & 1 & 0 \\
Malaise & 0 & 0 & 0 & 0 & 0 & 0 & 0 & 1 \\
Myalgia & 0 & 0 & 0 & 0 & 0 & 1 & 1 & 2 \\
\hline
\end{tabular}

The most common event was flu-like symptoms occurring within 24 hours and disappearing within 48 hours. The second most common event was epistaxis, i.e. blood-admixed nasal secretions. The side effects were dose-dependent and considered causally related to the treatment.

$30 \mu \mathrm{g}$. No other specific changes were revealed by the laboratory blood/plasma analysis.

AZD8848 produced dose-dependent influenza-like symptoms starting consistently at $100 \mu \mathrm{g}$ and leading to termination of dose escalations above $600 \mu \mathrm{g}$ (Table 2). The second most common effect was mild epistaxis, i.e. blood-admixed nasal secretions.

Following the experiments involving healthy individuals, patients with allergic rhinitis (examined out of season) were subjected to administration of AZD8848 (30 and $100 \mu \mathrm{g}$ ). No differences were observed in the

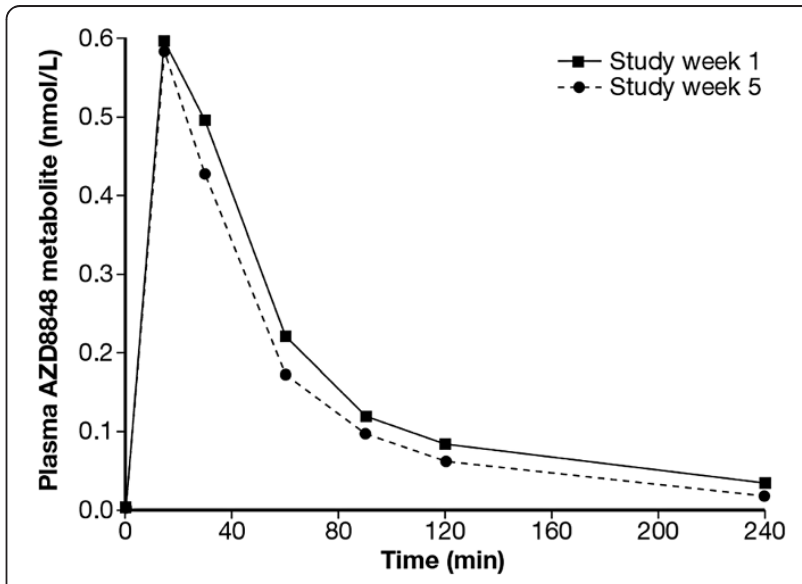

Figure 3 Mean plasma levels of AZD8848's acid metabolite from the first group of the repeat challenge/treatment study after administration of $60 \mu \mathrm{g}$ of the study drug. The metabolite increased rapidly and returned to baseline levels after four hours. 

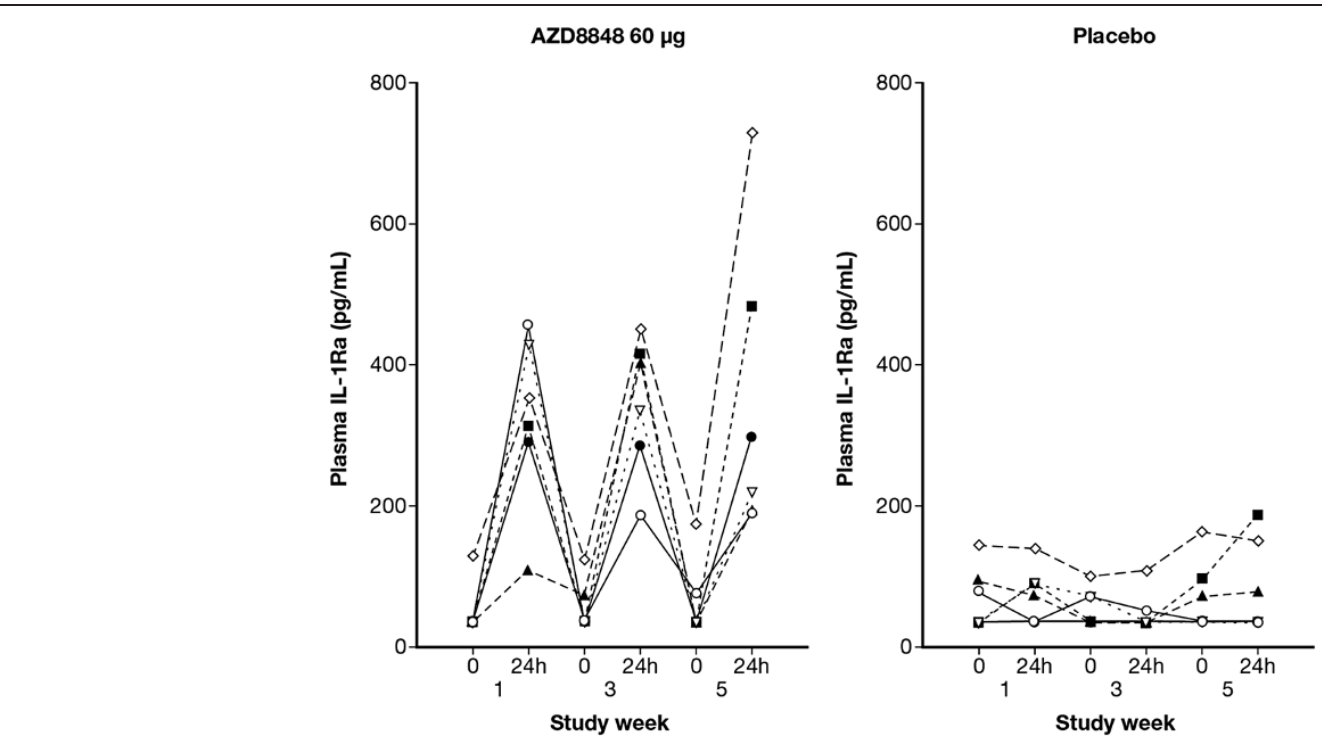

Figure 4 IL-1Ra in plasma obtained at Study weeks 1, 3, and 5 from the repeat challenge/treatment study (symbols indicate individual values: $\mathbf{n}=6$ ). IL-1Ra increased 24 hours after nasal administration of AZD8848 and the effect was consistent and repeatable $(p<0.001)$.

response profile to AZD8848 between these patients and the healthy individuals.

\section{Repeat challenge/treatment study}

AZD8848's acid metabolite was detected at doses of $30 \mu \mathrm{g}$ (data not shown) as well as $60 \mu \mathrm{g}$ (Figure 3) For the $60 \mu \mathrm{g}$ dose, as monitored on Study week 1 and 5, respectively, $C_{\max }$ was 0.58 and $0.57 \mathrm{nmol} / \mathrm{L}, t_{\max }$ was 17.2 and $20.2 \mathrm{~min}$, and $t_{1 / 2}$ was 0.83 and 1.26 hours.

Plasma levels of IL-1Ra, reflecting TLR7-induced type-1 IFN production, were consistently increased 24 hours after nasal administration of AZD8848 (Figure 4). For $60 \mu \mathrm{g}$, these changes reached statistical significance $(\mathrm{p}<0.001)$. (For $30 \mu \mathrm{g}$, comparative statistics was not carried out.)

In agreement with the single dose study, blood lymphocyte counts were consistently reduced after administration of AZD8848 in the repeat challenge/treatment study (Figure 2B). Further analysis indicated that this reflected uniform reductions across different lymphocyte subsets: CD3+, CD4+, CD8+, and CD20+ cells (data not shown).

The safety profile in the repeat dose/treatment study was similar to what is described for the single dose study above, with 35 and 24\% reporting flu-like symptoms and blood-admixed nasal secretions, respectively, at treatment with $60 \mu \mathrm{g}$ AZD8848 (c.f. 6 and 6\% for placebo). The symptoms subsided within 24 hours, and did not lead to any individual discontinuations. Two individuals did drop out of the study and both received $60 \mu \mathrm{g}$ AZD8848: one and two doses, respectively. One case was an AE (anorectal irritation, considered not associated with the treatment) and the other was an individual found to be wrongfully included.
In patients receiving placebo, in agreement with previous observations in this model [24], increases were observed for nasal symptoms, i.e. TNSS: total nasal symptom score, ten minutes after each allergen challenge. Morning and evening total nasal symptoms were also increased and consistent changes were observed from the third study day of the allergen challenge series.

AZD8848 $(60 \mu \mathrm{g})$ reduced nasal symptoms recorded ten minutes after allergen challenge from the fourth through the seventh day of the challenge series (i.e. five to eight days after the last dose of AZD8848) with an estimated effect size of 0.74 score units $(\mathrm{p}<0.05)$ (Figure 5$)$. For individual symptoms, reductions were observed for itching

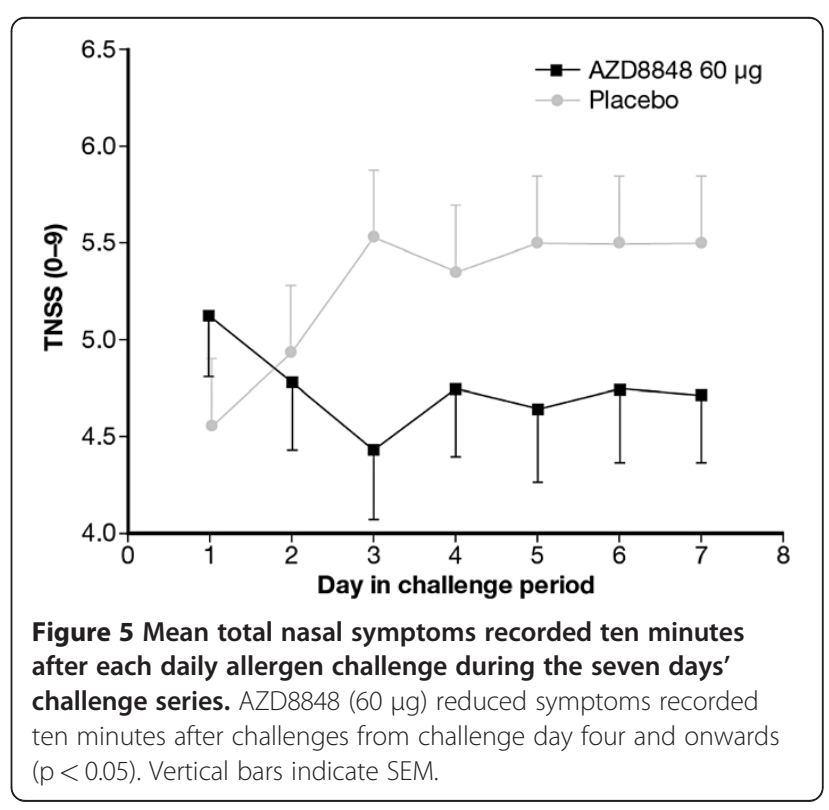


$(\mathrm{p}<0.05)$, sneezing $(\mathrm{p}<0.05)$, and blocked nose ( $<0.05$ ), but not for runny nose (data not shown).

Morning and evening symptoms were numerically reduced on challenge days two through five in patients receiving AZD8848 $(60 \mu \mathrm{g})$, but these effects failed to reach statistical significance (Figure 6): $\mathrm{p}>0.05$ for morning as well as evening symptoms.

On the day after the last allergen challenge, levels of $\alpha_{2}$-macroglobulin in nasal lavage fluids, reflecting plasma exudation, were lower in patients who had received $60 \mu \mathrm{g}$ AZD8848 and this was statistically significant compared to placebo $(\mathrm{p}<0.05)$ (Table 3$)$. Significantly lower levels of mast cell tryptase were also seen in these patients (c.f. placebo) $(\mathrm{p}<0.05)($ Table 3$)$.

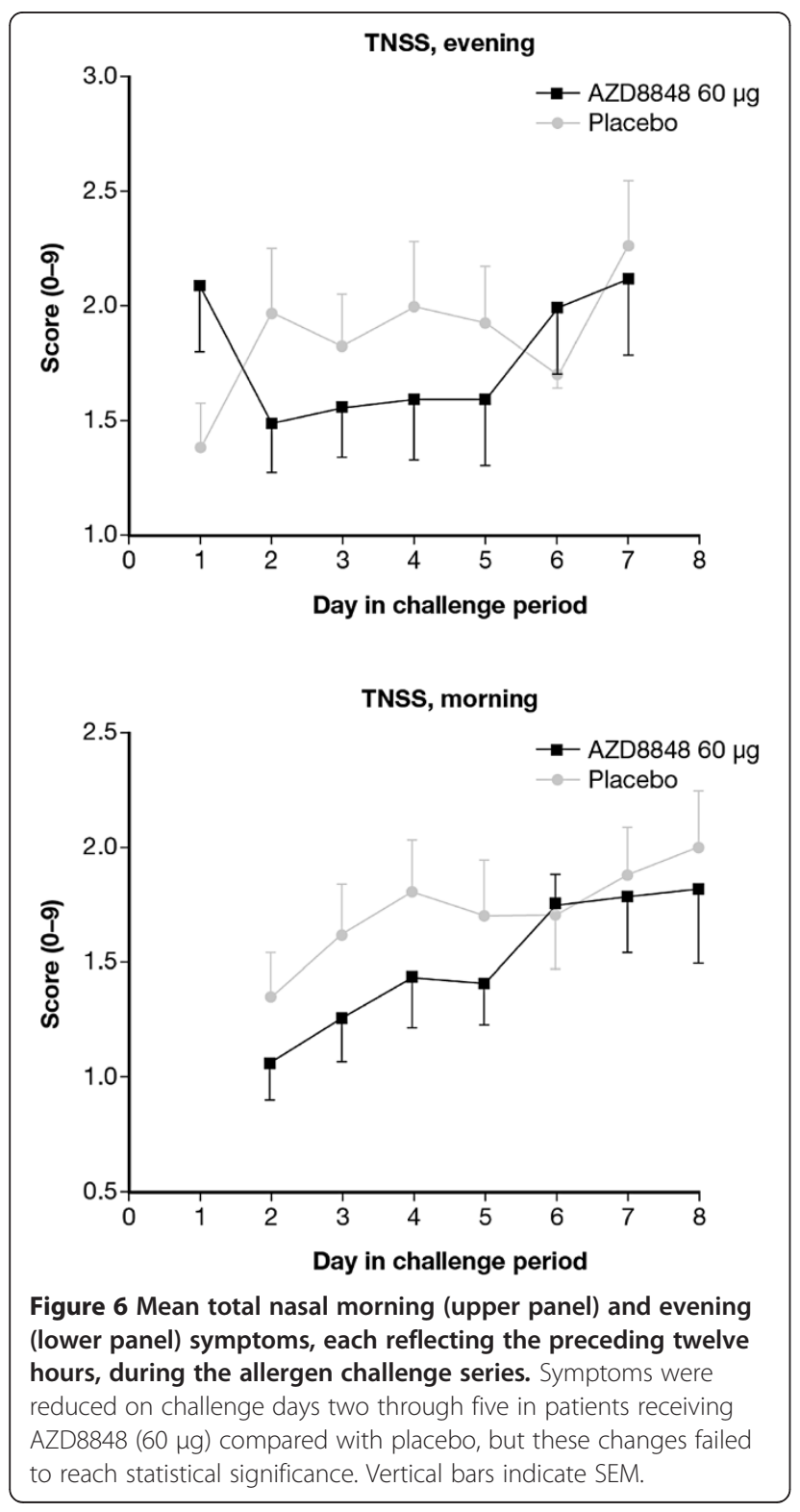

Table 3 Mean ratios (between AZD8848 and placebo) for levels of $a_{2}$-macroglobulin and tryptase, respectively, in nasal lavages obtained $\mathbf{2 4}$ hours after the last allergen challenge in the repeat challenge/treatment study

\begin{tabular}{llll}
\hline Variable & Mean ratio & $\mathbf{9 5 \% ~ C l}$ & P-value \\
\hline $\mathrm{a}_{2}$-Macroglobulin & 0.50 & $0.25-0.97$ & 0.020 \\
Tryptase & 0.62 & $0.35-1.10$ & 0.049 \\
\hline
\end{tabular}

$\mathrm{a}_{2}$-Macroglobulin was reduced in patients who had received AZD8848 $(p<0.05$, c.f. placebo). Similarly, lower levels of tryptase were observed in this group ( $p<0.05$, c.f. placebo).

\section{Discussion}

In these studies we demonstrate that repeated intranasal TLR7 stimulation is associated with reduced responsiveness to allergen in patients with allergic rhinitis. It is the first observation in man where TLR7 has been successfully evaluated as a therapeutic target for allergic airway inflammation.

The TLR7 agonist AZD8848 undergoes very rapid enzymatic degradation by butyrylcholinesterase: $t_{1 / 2}$ in human plasma is estimated to be 20 seconds [19]. In this study, this was reflected by undetectable plasma levels of the substance following nasal administration of doses up to $600 \mu \mathrm{g}$, while its acid metabolite, which is 1500 times less potent at the receptor [19], was detectable at doses of $30 \mu \mathrm{g}$ and above. Nevertheless, flu-like symptoms were reported, which were probably secondary to local TLR7 activation and a subsequent systemic increase in type-1 IFN. This possibility was indicated by the fivefold increase in plasma IL-1Ra following administration of AZD8848, known to reflect type-1 IFN production down-stream to TLR7 (i.e. proof of mechanism) $[21,26]$. In the context of the hygiene hypothesis, repeated administration of the TLR7 agonist AZD8848 may mimic repeated virus-like stimulation of the immune system.

In the repeat challenge/treatment study, acute symptoms in response to allergen were consistently reduced from the third day of the allergen challenge series in patients receiving the TLR7 agonist when compared to placebo, indicating a sustained effect of at least one week after the final dose of AZD8848. The same pattern was observed for the low-grade morning and evening symptoms, but these changes failed to reach statistical significance. In agreement with a symptom reducing effect, lavage fluid levels of tryptase and $\alpha_{2}$-macroglobulin, reflecting mast cell activity and inflammatory plasma exudation $[27,28]$, were also reduced. Our observations extend recent in vitro and animal reports on anti-allergic effects of AZD8848, indicating that repeated TLR7 stimulation reduces the responsiveness to allergen [19-23], and suggest that AZD8848 may be clinically effective in allergic rhinitis.

The observed reduction in responsiveness to allergen might reflect that the immune system was functionally 
skewed away from a Th2 response. If so, it did probably not represent repolarisation of T-lymphocytes (i.e. a change from Th2 to Th1 phenotype), as this study involved atopic individuals with established populations of memory T-cells with a life span of at least two to three years [29]. Arguably, the outcome was more likely a consequence of a functionally reduced responsiveness of memory Th2 lymphocytes. In this context, for future studies, it would be of interest to examine if prolonged treatment, i.e. a time period sufficient to induce true repolarisation of T-lymphocytes, could produce a more marked anti-allergic effect.

While the repeat challenge/treatment study demonstrated that $60 \mu \mathrm{g}$ of AZD8848 administered intranasally once weekly for five weeks induced a desired hyporesponsiveness to allergen, likely through activation of TLR7, further studies are warranted to optimize the effect. Preclinical data have indicated that more frequent administration of AZD8848 can produce more marked anti allergic effects (AstraZeneca: data on file). Furthermore, as demonstrated in a Brown Norway rat model of allergic rhinitis/asthma, both nasal and bronchial administration of AZD8848 can reduce the ability of a bronchial allergen challenge to produce bronchial airway eosinophilia and generate IL-13 [19], suggesting the possibility that nasal administration of AZD8848 may be effective in the treatment of asthma.

In this study, safety and tolerability of intranasal AZD8848 was evaluated parallel to the exploration of its anti-allergic effects. None of the patients treated with AZD8848 discontinued the study prematurely due to drug-related AE. Furthermore, standard laboratory indices (haematology, clinical chemistry, and urine analysis) were unaffected by the treatment, except for the anticipated transient reductions in blood lymphocyte counts. Moreover, vital signs (blood pressure, pulse, and body temperature) and continuous ECG were unaffected. However, dosedependent local side effects were common, albeit of mild intensity. These were dominated by blood-admixed nasal secretions and in these cases nasal inspection revealed superficial mucosal irritations/ulcerations. This effect, and the temporary flu-like symptoms that were experienced by a third of the patients, needs to be further evaluated in order to assess overall tolerability of intranasal AZD8848 as a potential treatment.

The body of knowledge on TLRs is increasing as their distribution and functions are outlined, along with potential associations with specific allergic and airway conditions [30,31] and their treatment, notably specific immunotherapy [32,33]. In the context of established allergic airway conditions, animal observations suggest that stimulation of TLRs (i.e. TLR3, TLR4, TLR7, TLR8, and TLR9) has a general potential to reduce allergen responsiveness. However, focusing on human conditions available observations are scarce. In patients with allergic asthma, a synthetic oligonucleotide containing immunostimulatory CpG motifs (acting on TLR9) was reported to increase the expression of IFN- $\gamma$ and IFN inducible genes without affecting allergen challenge induced changes [34], possibly reflecting that the dose employed was too low to produce an anti-allergic effect. In a report by Casale et al. [35], which focused on tolerability to topical CRX-675 (acting on TLR4), data on efficacy was not given in detail, but a decrease in allergen-induced nasal symptoms was reported in one of four treatment groups compared with placebo. Moreover, it was recently reported that nasal administration of a TLR8 agonist (i.e. VTZ-1463) improved symptoms of allergic rhinitis [36]. Taken together, available information suggests that TLR agonists are valid treatment targets for allergic airway disease.

The natural ligand for TLR7 is single stranded RNA. Accordingly, various respiratory viruses, e.g. influenza, corona, and potentially rhinovirus [37], may activate the receptor. In this context, it is of interest to consider the evidence indicating that respiratory viral infections often heighten the responsiveness to allergen and produce asthma exacerbations [38,39]. The possibility that acute pro-inflammatory effects of TLR7 stimulation may heighten the responsiveness to allergen while later effects may reduce allergen responsiveness suggests that the timing of interventions with TLR7 agonists in relation to allergen exposure is important. Further studies are warranted to explore this and to outline the benefits and risks of treatment with TLR7 agonists in allergic airway disease.

\section{Conclusion}

We conclude that repeated intranasal stimulation of TLR7 by AZD8848 has a potential to affect the immune system in a way that may result in a sustained reduction in the responsiveness to allergen in allergic rhinitis.

\section{Competing interests}

The work described in this manuscript was supported and funded through a collaboration with AstraZeneca and Dainippon Sumitomo Pharma. In the past five years, LG and MA have received project related financial support from AstraZeneca, Schering-Plough, Orexo, HealthCap (Biolipox/Orexo/LTB4 Sweden/CC10 Sweden), Bioglan, and Nares. LG and MA are shareholders in Nares (a company active in the field of allergic rhinitis). In the past five years, AC has received financial support from AstraZeneca and Mediplast. In the past five years, EH has received financial support from AstraZeneca, Grünenthal, and NovoNordisk. GA and AK are employed by AstraZeneca. LE and PN were employed by AstraZeneca when the study was conducted. CAE, JD, ILS, and HW declare no competing interests.

\section{Authors' contributions}

Conception, design and management: $L G, G A, A C, L E, E H, P N$. Patient examination: LG, CAE, MA, AC, JD, EH, PN, ILS, HW. Data input, drafting, revision and/or approval of manuscript: All. Statistics: LG, AC, AK. All authors read and approved the manuscript. 


\section{Acknowledgements}

The authors would like to thank Barbara Young for her contribution to the work. The authors would also like to thank Lena Glantz-Larsson, Charlotte Cervin-Hoberg, Malin Prahl, Josefin Mathisen, and Catarina Villalba for their assistance. The work described in this manuscript was supported and funded through a collaboration with AstraZeneca and Dainippon Sumitomo Pharma.

\section{Author details}

'Department of ORL, Head \& Neck Surgery, Skane University Hospital, Lund, Sweden. ${ }^{2}$ Department of ORL, Helsingborg Hospital, Helsingborg, Sweden. ${ }^{3}$ Research \& Development, AstraZeneca, Lund, Sweden. ${ }^{4}$ Department of Clinical Pharmacology, Skane University Hospital, Lund, Sweden.

Received: 8 March 2012 Accepted: 18 June 2012

Published: 22 June 2012

\section{References}

1. Strachan DP: Hay fever, hygiene, and household size. Br Med J 1989 299:1259-1260.

2. Del Prete G, Maggi E, Romagnani S: Human Th1 and Th2 cells: functional properties, mechanisms of regulation, and role in disease. Lab Invest 1994, 70:299-306.

3. Robinson DS, Hamid Q, Ying S, Tsicopoulos A, Barkans J, Bentley AM, Corrigan C, Durham SR, Kay AB: Predominant TH2-like bronchoalveolar Tlymphocyte population in atopic asthma. N Engl J Med 1992, 326:298-304.

4. Fujimura T, Yamanashi R, Masuzawa M, Fujita Y, Katsuoka K, Nishiyama S, Mitsuyama M, Nomoto K: Conversion of the CD4+ T cell profile from T (H2)-dominant type to $\mathrm{T}(\mathrm{H} 1)$-dominant type after varicella-zoster virus infection in atopic dermatitis. J Allergy Clin Immunol 1997, 100:274-282.

5. Medzhitov R, Janeway CA Jr: Decoding the patterns of self and nonself by the innate immune system. Science 2002, 296:298-300.

6. Takeuchi $\mathrm{O}$, Akira S: Pattern recognition receptors and inflammation. Cell 2010, 140:805-820

7. Gariboldi S, Palazzo M, Zanobbio L, Dusio GF, Mauro V, Solimene U, Cardani D, Mantovani M, Rumio C: Low dose oral administration of cytokines for treatment of allergic asthma. Pulm Pharmacol Ther 2009, 22:497-510.

8. Li X, Yang A, Huang H, Zhang X, Town J, Davis B, Cockcroft DW, Gordon JR: Induction of type $2 \mathrm{~T}$ helper cell allergen tolerance by IL-10-differentiated regulatory dendritic cells. Am J Respir Crit Care Med 2010, 42:190-199.

9. Manetti R, Parronchi P, Giudizi MG, Piccinni MP, Maggi E, Trinchieri G, Romagnani S: Natural killer cell stimulatory factor (interleukin 12 [IL-12]) induces T helper type 1 (Th1)-specific immune responses and inhibits the development of IL-4-producing Th cells. J Exp Med 1993, 177:1 199-1204.

10. Mosmann TR, Moore KW: The role of IL-10 in crossregulation of TH1 and TH2 responses. Immunol Today 1991, 12:A49-A53.

11. Camateros P, Tamaoka M, Hassan M, Marino R, Moisan J, Marion D, Guiot MC Martin JG, Radzioch D: Chronic asthma-induced airway remodeling is prevented by toll-like receptor-7/8 ligand S28463. Am J Respir Crit Care Med 2007, 175:1241-1249.

12. Moisan J, Camateros $P$, Thuraisingam $T$, Marion $D$, Koohsari $H$, Martin $P$, Boghdady ML, Ding A, Gaestel M, Guiot MC, et al: TLR7 ligand prevents allergen-induced airway hyperresponsiveness and eosinophilia in allergic asthma by a MYD88-dependent and MK2-independent pathway. Am J Physiol Lung Cell Mol Physiol 2006, 290:L987-L995.

13. Sel S, Wegmann M, Bauer S, Garn H, Alber G, Renz H: Immunomodulatory effects of viral TLR ligands on experimental asthma depend on the additive effects of IL-12 and IL-10. J Immuno/ 2007, 178:7805-7813.

14. Broide D, Schwarze J, Tighe H, Gifford T, Nguyen MD, Malek S, Van Uden J, Martin-Orozco E, Gelfand EW, Raz E: Immunostimulatory DNA sequences inhibit IL-5, eosinophilic inflammation, and airway hyperresponsiveness in mice. J Immunol 1998, 161:7054-7062.

15. Broide DH, Stachnick G, Castaneda D, Nayar J, Miller M, Cho JY, Roman M Zubeldia J, Hayashi T, Raz E: Systemic administration of immunostimulatory DNA sequences mediates reversible inhibition of Th2 responses in a mouse model of asthma. J Clin Immunol 2001, 21:175-182.

16. Fanucchi MV, Schelegle ES, Baker GL, Evans MJ, McDonald RJ, Gershwin Lل, Raz E, Hyde DM, Plopper CG, Miller LA: Immunostimulatory oligonucleotides attenuate airways remodeling in allergic monkeys. Am J Respir Crit Care Med 2004, 170:1153-1157.

17. Serebrisky D, Teper AA, Huang CK, Lee SY, Zhang TF, Schofield BH, Kattan M, Sampson HA, Li XM: CpG oligodeoxynucleotides can reverse Th2-associated allergic airway responses and alter the B7.1/B7.2 expression in a murine model of asthma. J Immunol 2000, 165:5906-5912.

18. Sur S, Wild JS, Choudhury BK, Sur N, Alam R, Klinman DM: Long term prevention of allergic lung inflammation in a mouse model of asthma by CpG oligodeoxynucleotides. J Immunol 1999, 162:6284-6293.

19. Bell J, Britt J, Biffen M, Ferguson D, Aoki M, Eiho K, Bahl A, Takaku H, Murray C: AZD8848/DSP-3025 is a novel potent TLR7 agonist ante-drug that demonstrates negligible systemic activity and a prolonged period of control after cessation of weekly dosing in a Brown Norway rat ovalbumin challenge model. Am J Respir Crit Care Med 2010, 181:A5688.

20. Aoki M, Bell J, Ikeda K, Onishi M, Eiho K, Tomizawa H, Takaku H, Kitaura M: Weekly dosing of AZD8848/DSP-3025, a novel TLR7 agonist ante-drug, demonstrates a prolonged period of control against markers of pulmonary inflammation in an allergen challenge model in the mouse. Am J Respir Crit Care Med 2010, 181:A5689.

21. Biffen M, Matsui H, Edwards S, Satterthwaite G, Doyle I, Holness E, Leishman A, Eiho K, Aoki M, Tomizawa $\mathrm{H}$, et al: Biological activity of novel TLR7 ante-drug agonists for the treatment of allergic diseases. Am J Respir Crit Care Med 2010, 181:A4265

22. Matsui H, Tomizawa H, Eiho K, Edwards S, Biffen M, Leishman A, Murray C, Takaku H, Hayashi H: Mechanisms of inhibition of type-2 cytokines by novel ante-drug TLR7 agonists. Am J Respir Crit Care Med 2010, 181:A4041.

23. Ikeda K, Bell J, Aoki M, Nakayama T, Eiho K, Onishi M, Takaku H, Nishikaku F: AZD8848/DSP-3025, A Novel TLR7 Agonist Ante-Drug, Demonstrates Efficacy Against Airway Obstruction And Other Inflammatory Endpoints In Guinea Pig Models Of Rhinitis And Asthma With Acute And Weekly Dosing. Am J Respir Crit Care Med 2010, 181:A4242.

24. Greiff L, Ahlstrom-Emanuelsson C, Bahl A, Bengtsson T, Dahlstrom K, Erjefalt J, Widegren $\mathrm{H}$, Andersson M: Effects of a dual CCR3 and H1-antagonist on symptoms and eosinophilic inflammation in allergic rhinitis. Respir Res 2010, $11: 17$

25. Greiff L, Pipkorn U, Alkner U, Persson CG: The 'nasal pool' device applies controlled concentrations of solutes on human nasal airway mucosa and samples its surface exudations/secretions. Clin Exp Allergy 1990, 20:253-259.

26. Sims $P$, Coffman RL, Hessel EM: Biomarkers measuring the activity of Tolllike receptor ligands in clinical development programs. Methods $\mathrm{Mol} \mathrm{Biol}$ 2009, 517:415-440.

27. Castells M, Schwartz LB: Tryptase levels in nasal-lavage fluid as an indicator of the immediate allergic response. J Allergy Clin Immunol 1988, 82:348-355.

28. Persson CG, Erjefalt JS, Greiff L, Andersson M, Erjefalt I, Godfrey RW, Korsgren M, Linden M, Sundler F, Svensson C: Plasma-derived proteins in airway defence, disease and repair of epithelial injury. Eur Respir J 1998, 11:958-970.

29. Umeki S, Kusunoki Y, Cologne JB, Iwamoto KS, Hirai Y, Seyama T, Ohama K, Kyoizumi S: Lifespan of human memory T-cells in the absence of T-cell receptor expression. Immunol Lett 1998, 62:99-104.

30. Moller-Larsen S, Nyegaard M, Haagerup A, Vestbo J, Kruse TA, Borglum AD: Association analysis identifies TLR7 and TLR8 as novel risk genes in asthma and related disorders. Thorax 2008, 63:1064-1069.

31. Roponen M, Yerkovich ST, Hollams E, Sly PD, Holt PG, Upham JW: Toll-like receptor 7 function is reduced in adolescents with asthma. Eur Respir $J$ 2010, 35:64-71.

32. Creticos PS, Schroeder JT, Hamilton RG, Balcer-Whaley SL, Khattignavong AP, Lindblad R, Li H, Coffman R, Seyfert V, Eiden JJ, Broide D: Immunotherapy with a ragweed-toll-like receptor 9 agonist vaccine for allergic rhinitis. $N$ Engl J Med 2006, 355:1445-1455.

33. Tulic MK, Fiset PO, Christodoulopoulos P, Vaillancourt P, Desrosiers M, Lavigne F, Eiden J, Hamid Q: Amb a 1-immunostimulatory oligodeoxynucleotide conjugate immunotherapy decreases the nasal inflammatory response. J Allergy Clin Immunol 2004, 113:235-241.

34. Gauvreau GM, Hessel EM, Boulet LP, Coffman RL, O'Byrne PM: Immunostimulatory sequences regulate interferon-inducible genes but not allergic airway responses. Am J Respir Crit Care Med 2006, 174:15-20.

35. Casale TB, Kessler J, Romero FA: Safety of the intranasal toll-like receptor 4 agonist CRX-675 in allergic rhinitis. Ann Allergy Asthma Immunol 2006, 97:454-456.

36. Horak F, Zieglmayer $P$, Zieglmayer R, Lemell $P$, Newkirk M, Manjarrez K Randall T, Hershberg R: Intranasal Toll-like receptor 8 agonist (VTX-1463) significantly improves symptoms of allergic rhinitis in a randomized, placebo-controlled trial. J Allergy Clin Immunol 2011, 127:AB199. 
37. Wang Q, Nagarkar DR, Bowman ER, Schneider D, Gosangi B, Lei J, Zhao Y, McHenry CL, Burgens RV, Miller DJ, et al: Role of double-stranded RNA pattern recognition receptors in rhinovirus-induced airway epithelial cell responses. J Immunol 2009, 183:6989-6997.

38. Greiff $L$, Andersson M, Svensson C, Linden M, Myint S, Persson CG: Allergen challenge-induced acute exudation of IL-8, ECP and alpha2-

macroglobulin in human rhinovirus-induced common colds. Eur Respir J 1999, 13:41-47.

39. Johnston SL, Pattemore PK, Sanderson G, Smith S, Campbell MJ, Josephs LK, Cunningham A, Robinson BS, Myint SH, Ward ME, et al: The relationship between upper respiratory infections and hospital admissions for asthma: a time-trend analysis. Am J Respir Crit Care Med 1996, 154:654-660.

doi:10.1186/1465-9921-13-53

Cite this article as: Greiff et al:: Repeated intranasal TLR7 stimulation reduces allergen responsiveness in allergic rhinitis. Respiratory Research 2012 13:53.

\section{Submit your next manuscript to BioMed Central and take full advantage of:}

- Convenient online submission

- Thorough peer review

- No space constraints or color figure charges

- Immediate publication on acceptance

- Inclusion in PubMed, CAS, Scopus and Google Scholar

- Research which is freely available for redistribution 